\title{
Diagnostic laparoscopy in the evaluation of tubal factor in cases of infertility
}

\author{
Arpana Dipakbhai Chaudhari ${ }^{1}$, Anilkumar Mathurbhai Baria ${ }^{2}$, Upendra Rameshbhai \\ Chaudhari $^{3}$, Grishma T. Dixit ${ }^{4}$, Nilesh Thakor ${ }^{5 *}$
}

\author{
${ }^{1}$ Department of Obstetrics and Gynecology, GMERS Medical College, Valsad, Gujarat, India \\ ${ }^{2}$ Department of Obstetrics and Gynecology, GMERS Medical College, Himmatnagar, Gujarat, India \\ ${ }^{3}$ Department of Pediatrics, Government Medical College, Surat, Gujarat, India \\ ${ }^{4}$ Department of Community Medicine, B. J. Medical College, Ahmedabad, Gujarat, India \\ ${ }_{5}^{5}$ Department of Community Medicine, GMERS Medical College and Hospital, Gandhinagar, Gujarat, India
}

Received: 02 March 2017

Accepted: 08 March 2017

*Correspondence:

Dr. Nilesh Thakor,

E-mail: drnileshthakor@yahoo.co.in

Copyright: ( $)$ the author(s), publisher and licensee Medip Academy. This is an open-access article distributed under the terms of the Creative Commons Attribution Non-Commercial License, which permits unrestricted non-commercial use, distribution, and reproduction in any medium, provided the original work is properly cited.

\section{ABSTRACT}

Background: Tubal factor infertility accounts for a large portion of female factor infertility. The most prevalent cause of tubal factor infertility is pelvic inflammatory disease and acute salpingitis. Tubal patency can be diagnosed by hysterosalpingography (HSG) or laparoscopy with chromopertubation. The aim of this study was to determine the role of laparoscopy in the evaluation of tubal factor in infertile women.

Methods: Sixty women presenting with complaints of primary and secondary infertility were investigated for tubal disease by laparoscopy at at Smt. NHL Municipal Medical College, Ahmedabad during July 2011 to September 2013. Tubal patency was tested by chromopertubation using Methylene blue dye.

Results: Thirty-five $(58.3 \%)$ patients were in primary infertility group while $25(41.7 \%)$ patients were in secondary infertility group. $80 \%$ women were in the age group of 21 to 30 years. In $49 \%$ of women, the duration of infertility was between 2 to 4 years whereas $17 \%$ cases had been infertile for 6 to 10 years. Diagnostic laparoscopy and findings of chromopertubation revealed unilateral blockage in $37 \%$ of cases, bilateral blockage had seen in $23 \%$ of cases, endometriosis was seen in $9 \%$ of cases and adhesion in $7 \%$ of cases.

Conclusions: Unilateral and bilateral tubal blockade was detected in $60 \%$ of cases of infertile women.

Keywords: Chromopertubation, Infertility, Laparoscopy, Tubal factors, Tubal blockadge

\section{INTRODUCTION}

The desire to reproduce is an intensely motivating human force. Couples may also experience strong religious, cultural and social pressure to conceive. Infertility is a life crisis for them. The number of couples seeking medical help for infertility is increasing dramatically (from $8 \%$ to $10-15 \%$ ). ${ }^{1,2}$

Tubal disease is among the most common causes of infertility and is the primary diagnosis in approximately
$30 \%$ of female infertility cases. The fallopian tubes are very delicate structures that are responsible for picking up the egg and providing the site for fertilization of the egg as well as early embryo development and transport to the uterine cavity. The tubes may be damaged by infections or other pelvic conditions. A previous history of pelvic inflammatory disease, tubal surgery, ectopic pregnancy, ruptured appendix, ovarian surgery or septic abortion strongly suggests the possibility of tubal disease. The most prevalent cause of tubal factor infertility is pelvic inflammatory disease and acute salpingitis. The incidence of tubal damage after one episode of pelvic infection is 
approximately 12\%, 23\% after two episodes and 54\% after three episodes. ${ }^{3,4}$ Proximal, distal, and peritubal damage can be caused by a number of pathologic processes such as inflammation, endometriosis, and surgical trauma. ${ }^{5}$

Today in the era of scientific advancement and technology, newer diagnostic and operative modalities have paved the path for further insight into this problem. Laparoscopy has emerged in recent years as an accurate method of assessing, evaluating and treating infertility..$^{6,7,8}$

Laparoscopy and chromopertubation is widely considered the gold standard test for investigating tubal patency. Additionally, it allows assessment for peritubal disease, adhesions and endometriosis. This has led to a recommendation by the NICE (UK) that women suspected of having comorbidities (such as endometriosis and pelvic inflammatory disease should undergo laparoscopy so that pelvic and tubal pathology can both be assessed. ${ }^{9}$ The aim of the study was to evaluate the role of laparoscopy in diagnosis of infertile women with tubal factors.

\section{METHODS}

Sixty women presenting with complaints of primary and secondary infertility were investigated for tubal disease by laparoscopy at Smt. NHL Municipal Medical College, Ahmedabad during July 2011 to September 2013. Inclusion criteria were no prior pelvic surgery, no history of pelvic infection, normal bimanual pelvic examination, and normal semen parameters of partner. Those patients who had medical disorders and contraindication for laparoscopy were excluded from study. Laparoscopy was scheduled in proliferative phase of menstrual cycle.

Laparoscopy was performed under general anesthesia. A one $\mathrm{cm}$ incision was made within or just below the lower edge of the umbilicus. Through this incision the abdominal cavity is inflated with carbon dioxide gas and pneumoperitoneum being obtained. A trocar was inserted in the same region. The cannula of the trocar was left, and the trocar was pulled out. Then a laparoscope was introduced through the cannula. During the procedure, the pelvis was inspected, including uterus, fallopian tubes, uterosacral ligaments, and Pouch of Douglas. The tubes were inspected for any abnormality in their length and shape. Both ovaries were examined regarding their size, shape, thickness of peripheral follicles.

Peritubal, periovarian and omental adhesions, tuboovarian masses, endometriotic deposits, fibroid, presence of fluid in the Pouch of Douglas or any other pathology, if present was noted. The patency of fallopian tubes was ascertained by injecting methylene blue or Gentian violet into the uterine cavity and its spill through the fimbrial ends was checked. Variables were age, primary and secondary infertility, duration of infertility, tubal patency (yes or no), bilateral tubal block and unilateral tubal block. The study protocol was approved by the Institutional ethics committee. Patients were enrolled after having provided their informed written consent.

\section{RESULTS}

There were $35(58.3 \%)$ cases of primary infertility and 25 $(41.7 \%)$ cases of secondary infertility. $80 \%$ women were in the age group of 21 to 30 years (Table 1 ).

Table 1: Age distribution in cases of primary and secondary infertility.

\begin{tabular}{|lllllll|}
\hline \multirow{2}{*}{ Age (years) } & \multicolumn{2}{l}{$\begin{array}{l}\text { Primary } \\
\text { infertility }\end{array}$} & \multicolumn{2}{l}{$\begin{array}{l}\text { Secondary } \\
\text { infertility }\end{array}$} & \multicolumn{2}{l|}{ Total } \\
\cline { 2 - 7 } & No. & \% & No. & \% & No. & \% \\
\hline $21-25$ & 21 & 35.0 & 05 & 8.3 & 26 & 43.3 \\
\hline $26-30$ & 08 & 13.3 & 14 & 23.3 & 22 & 36.7 \\
\hline$>=30$ & 06 & 10.0 & 06 & 10.0 & 12 & 20.0 \\
\hline Total & 35 & 58.3 & 25 & 41.7 & 60 & 100 \\
\hline
\end{tabular}

In $49 \%$ of women, the duration of infertility was between 2 to 4 years whereas $23 \%$ cases had been infertile for 5 to 6 years (Table 2). 64\% women had regular menstruation while $36 \%$ had irregular cycles (Table 2 ).

Table 2: Duration of infertility.

\begin{tabular}{|lll|}
\hline Duration of infertility & No. of Patients & $\%$ \\
\hline 2-4 years & 29 & 49 \\
\hline 5-6 years & 14 & 23 \\
\hline Above 6 years & 17 & 28 \\
\hline Total & 60 & 100 \\
\hline
\end{tabular}

Diagnostic laparoscopy and findings of chromopertubation revealed unilateral blockage in $37 \%$ of cases, bilateral blockage had seen in $23 \%$ of cases, endometriosis was seen in $9 \%$ of cases, adhesion in $7 \%$ of cases, hydrosalphinx in $10 \%$ of cases and tubo-ovarian mass in $3 \%$ of cases (Table 3 ).

Table 3: Findings of diagnostic laparoscopy and chromopertubation.

\begin{tabular}{|lll|}
\hline Tubal Factors & Number & $\%$ \\
\hline Unilateral blockage & 22 & 37 \\
\hline Bilateral blockage & 14 & 23 \\
\hline Endometriosis & 09 & 15 \\
\hline Adhesion & 07 & 12 \\
\hline Hydrosalphinx & 06 & 10 \\
\hline Tubo-ovarian mass & 02 & 03 \\
\hline Total & 60 & 100 \\
\hline
\end{tabular}

Out of total 22 cases of unilateral blockage, $11(50 \%)$ cases has proximal tubal blockage and $9(41 \%)$ cases had distal tubal blockage. Only 2 cases had bipolar tubal blocks. Out of total 14 cases of bilateral blockage, 8 
(57\%) cases had Pelvic Inflammatory Disease (PID) and $6(43 \%)$ cases had tuberculosis. Out of 60 cases, 45 had tubal factors of infertility in pelvic inflammatory disease. Out of 45,22 cases $(49 \%)$ had unilateral blockage and 8 cases (17\%) had bilateral blocks followed by hydrosalphinx, peritubal adhesions, adhesions in pouch of Douglas and tubo-ovarian mass in $13 \%, 11 \%, 5 \%$ and $5 \%$ respectively.

Table 4: Tubal factors of infertility in pelvic inflammatory disease.

\begin{tabular}{|lll|}
\hline & Number & $\%$ \\
\hline Unilateral blocks & 22 & 49 \\
\hline Bilateral blocks & 08 & 17 \\
\hline Hydrosalpinx & 06 & 13 \\
\hline Peritubal adhesions & 05 & 11 \\
\hline Adhesion in pouch of Douglas & 02 & 05 \\
\hline Tubo-ovarian mass & 02 & 05 \\
\hline Total & 45 & 100 \\
\hline
\end{tabular}

\section{DISCUSSION}

In present study diagnostic laparoscopy and findings of chromopertubation revealed unilateral blockage in $37 \%$ of cases, bilateral blockage had seen in $23 \%$ of cases. In Shetty SK et al tubal pathology was detected in $66 \%$ cases and bilateral tubal block in $8 \%$ cases and unilateral block in $28 \%$ cases. $^{9}$ These observations illustrate that the prevalence of tubal pathology in women complaining of infertility is high in our community. In Ikechebelu JI et al, $39.5 \%$ women had normal patent tubes while $(60.4 \%)$ had tubal pathologies like bilateral tubal occlusion in $(38.3 \%)$ and unilateral tubal occlusion in $(22.1 \%)$ women. ${ }^{10}$

In present study, out of total 22 cases of unilateral blockage, $11(50 \%)$ cases has proximal tubal blockage and $9(41 \%)$ cases had distal tubal blockage. Only 2 cases had bipolar tubal blocks. Out of total 14 cases of bilateral blockage, $8(57 \%)$ cases had Pelvic Inflammatory Disease (PID) and 6 (43\%) cases had tuberculosis. In Shetty SK et al, nonspecific pelvic inflammatory disease was observed in $15(44 \%)$ cases in primary infertility and $8(50 \%)$ cases in secondary infertility whereas Aziz N et al, Pelvic inflammatory disease was reported in $1(3.1 \%)$ and $2(16.7 \%)$ cases of primary and secondary infertility respectively. ${ }^{9,11}$ The common finding was tubal blockage in $7(21.9 \%)$ and $6(33.3 \%)$ cases of primary and secondary infertility respectively. After one episode of PID, a woman has an estimated $15 \%$ chance of infertility. After two episodes, the risk rises to $35 \%$. After three episodes, the risk for infertility is nearly $75 \%$.

In present study, endometriosis was seen in $9 \%$ of cases, adhesion $7 \%$ of cases, hydrosalphinx in $10 \%$ of cases and tubo-ovarian mass in $3 \%$ of cases. In Shetty SK et al, endometriosis was observed in $12(24 \%)$ cases but significant peritubal adhesions were found in $4(8 \%)$ cases whereas Aziz $\mathrm{N}$ et al reported endometriosis in 6 $(12 \%)$ cases and peritubal and peri-ovarian adhesions in 6 $(12 \%)$ cases. $^{9,11}$

In present study out of total 14 cases of bilateral blockage, $8(57 \%)$ cases had Pelvic Inflammatory Disease (PID) and $6(43 \%)$ cases had tuberculosis. In Shetty SK et al, the diagnosis of genital tuberculosis was made by laparoscopy in $1(2 \%)$ cases. $^{9}$ Bilateral tubal block was seen in the case. Sharma JB et al studied laparoscopic findings in genital $\mathrm{TB}$ in $47.1 \%$ cases. $^{12}$ Genital tuberculosis is common in India and a combination of clinical and laparoscopic diagnoses, along with endometrial histopathologic studies, acid-fast bacillus culture, and polymerase chain reaction assays provides the best available method for the diagnosis of genital tuberculosis in infertile women. ${ }^{13}$ However, study done in single college of Gandhinagar city limits us to generalize the results. There is definitely a need for wellplanned, large-scale studies to evaluate the role of laparoscopy in diagnosis of infertile women with tubal factors.

\section{CONCLUSION}

Unilateral and bilateral tubal blockade was detected in $60 \%$ of cases of infertile women in this study. These observations suggest that the use of laparoscopy and chromopertubation test should be recommended as a first step in the investigation of infertile women with tubal factor.

Funding: No funding sources

Conflict of interest: None declared

Ethical approval: The study was approved by the Institutional Ethics Committee

\section{REFERENCES}

1. Speroff L. Female infertility. In: Leon Speroff, Marc A. Fritz, eds. Clinical Gynecologic Endocrinology and Infertility. 17th ed. Philadelphia: Lippincott Williams and Wilkins; 2005:1003-58.

2. Padubidri VG. Pathology of Conception. In: Padubidri VG, Daftary SN, eds. Shaw: Text book of Gynecology. 14th ed. Noida: Reed Elsevier India Pvt. Ltd; 2008:198-9.

3. Dun EC, Nezhat CH. Tubal factor infertility: diagnosis and management in the era of assisted reproductive technology. Obstet Gynecol Clin North Am. 2012;39(4):551-66.

4. Muzii L, Sereni MI, Battista C, Zullo MA, Tambone V, Angioli R. Tubo-peritoneal factor of infertility: diagnosis and treatment. Clin Ter. 2010;161(1):7785.

5. Confino E, Radwanska E. Tubal factors in infertility. Curr Opin Obstet Gynecol. 1992;4(2):197-202.

6. Gomel V, Taylor PJ. History of laparoscopy. In: Gomel V, Taylor PJ, eds. Diagnostic and Operative 
Gynecologic Laparoscopy. 1st ed. St. Louis: Mosby Year Book Medical Publishers; 1995:46-62.

7. Coltart TM. Laparoscopy in the diagnosis of tubal patency. BJOG. 1970;77:69-71.

8. Chakraborti DK, Kole SK. Diagnostic laparoscopy in gynecologic disorders. J Obstet Gynecol India. 1990;40:262-5.

9. Shetty SK, Shetty H, Rai S. Laparoscopic evaluation of tubal factor in cases of infertility. Int $\mathrm{J}$ Reprod Contracept Obstet Gynecol. 2013;2:410-3.

10. Ikechebelu JI, Mbamara SU. Should laparoscopy and dye test be a first line evaluation for infertile women in southeast Nigeria? Niger J Med. 2011;20(4):462-5.

11. Aziz N. Laparoscopic evaluation of female factors in infertility. J Coll Physicians Surg Pak. 2010;20(10):649-52.
12. Sharma JB, Roy KK, Pushparaj M, Kumar S, Malhotra N, Mittal S. Laparoscopic findings in female genital tuberculosis. Arch Gynecol Obstet. 2008;278(4):359-64.

13. Gupta N, Sharma JB, Mittal S, Singh N, Misra R, Kukreja M. Genital tuberculosis in Indian infertility patients. Int J Gynaecol Obstet. 2007;97(2):135-8.

Cite this article as: Chaudhari $\mathrm{AD}$, Baria $\mathrm{AM}$, Chaudhari UR, Dixit GT, Thakor N. Diagnostic laparoscopy in the evaluation of tubal factor in cases of infertility. Int J Reprod Contracept Obstet Gynecol 2017;6:1275-8. 